Article

\title{
Windows of Opportunity in the CoPS's Catch-Up Process: A Case Study of China's High-Speed Train Industry
}

\author{
Han Huang ${ }^{1,2}{ }^{\oplus}$, Jie Xiong ${ }^{3}$ and Junfang Zhang ${ }^{1,4, *}$ \\ 1 School of Management, Huazhong University of Science and Technology, Wuhan 430074, China; \\ hwang.han@outlook.com \\ 2 School of Management, Wuhan Technology and Business University, Wuhan 430065, China \\ 3 Department of Strategy, Entrepreneurship \& International Business, ESSCA School of Management, \\ 49003 Angers, France; jie.xiong@essca.fr \\ 4 Center for Post-Doctoral Studies of Shenzhen Airlines Co. LTD., Shenzhen 518128, China \\ * Correspondence: zhang_junfang@foxmail.com
}

\section{check for}

updates

Citation: Huang, H.; Xiong, J.; Zhang, J. Windows of Opportunity in the CoPS's Catch-Up Process: A Case Study of China's High-Speed Train Industry. Sustainability 2021, 13, 2144 https://doi.org/10.3390/su13042144

Academic Editor: Luigi Dell'Olio

Received: 30 January 2021

Accepted: 9 February 2021

Published: 17 February 2021

Publisher's Note: MDPI stays neutral with regard to jurisdictional claims in published maps and institutional affiliations.

Copyright: (c) 2021 by the authors. Licensee MDPI, Basel, Switzerland. This article is an open access article distributed under the terms and conditions of the Creative Commons Attribution (CC BY) license (https:/ / creativecommons.org/licenses/by/ $4.0 /)$.

\begin{abstract}
Over the last 20 years, the rapid development of high-speed Chinese trains has provided valuable guidelines to countries and companies eager to develop their complex product and system (CoPS) sectors. CoPS refers to the high cost and technology-intensive systems, networks, infrastructure and engineering constructs, and services. Although established studies highlight the importance of CoPS to the economy and development of a country, especially those that have yet to develop high-speed rail, scholars have not paid much attention to investigating the catch-up of CoPS industries from the windows of opportunity perspective. We aimed to fill in this research gap by analyzing the successful catch-up of Chinese high-speed trains. Based on a longitudinal case study of this industry, we analyzed and detailed the mechanisms of the catch-up process of a typical CoPS sector and its development. Our results enrich the literature of the catch-up process, CoPS, and the studies of windows of opportunity. In particular, we show that the windows of opportunity that emerge in the catch-up process of CoPS have the characteristics of endogeneity, asymmetry, and relevance. Moreover, our study further indicates that the endogenous windows of opportunity regarding policy result in the development of later windows of technology and demand. We also find that the technology's windows of opportunity consist of the window to broaden the technology width and the window to deepen the technology depth of latecomers. In addition to theoretical contributions, our findings can help policymakers of latecomer countries better formulate CoPS industrial policies, followed by a gradual progress in successfully catch-up with the leading countries.
\end{abstract}

Keywords: catch-up; windows of opportunity; complex products and systems; technology capabilities; China's high-speed train industry

\section{Introduction}

The rapid development of China's railway transportation industry has drawn much attention from academia and practitioners over the last decade. By the end of 2020, the overall mileage of the high-speed railways in operation in China reached 37,900 km [1], whose total length is much higher than the combined mileage of high-speed railways in operation in all other countries [2]. Along with the continuous growth of high-speed railway mileage in China, we witnessed the remarkable improvement of China's technological innovation capability in the field of high-speed train manufacturing.

In as early as 2003, China started its acceleration of railway production via imitation of advanced foreign products and technologies, followed by the gradual enhancements of its domestic research and development (R\&D) as well as acquiring the key technologies required, and finally manufacturing Chinese standard high-speed trains in 2017. It took as little as 15 years for China to progress from relying on imported technology to endogenous innovation. This remarkably fast development is widely considered a rare 
innovation process in the economic history of China. For instance, as a manifestation of technological innovation, patents surged in China's high-speed train industry during the industry's development. Figure 1 illustrates the changes in the number of patents of China's largest high-speed train manufacturer, Changchun Railway Vehicles Co., Ltd. (Changchun, China) of China Railway Rolling Stock Corporation (CRRC, Beijing, China), for a total of 20 years from 2000 to 2019 (data source: patent database from the China national knowledge infrastructure).

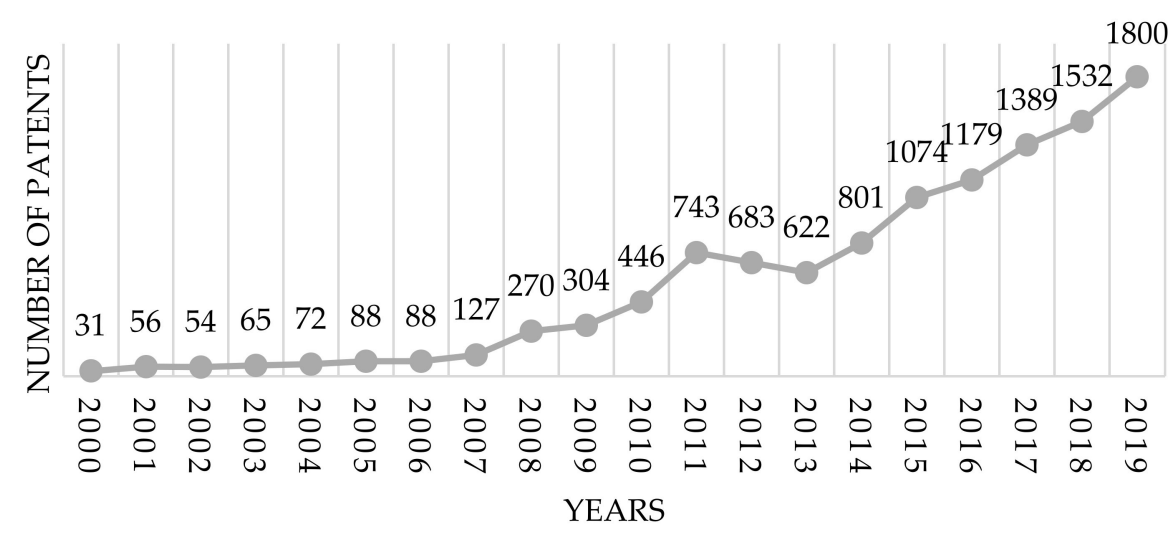

Figure 1. Patents of Changchun Railway Vehicles Co., Ltd. of China Railway Rolling Stock Corporation (CRRC, Beijing, China) (2000-2019).

Figure 1 shows two clear tendencies: the number of patents has been increasing year by year, and two clear turning points were formed in 2008 and 2013. The gradual increase in the number of patents reflects both the increasing technological capability of CRRC and the gradually narrowing gaps between CRRC and the industry leaders. In particular, by 2017, domestically produced high-speed trains were no longer derivatives of foreign technology but instead produced by their own technical standards, demonstrating that Chinese rail technology has reached parity with global levels. Since 2020, the Fuxing high-speed trains that have been gradually exported to Thailand, Indonesia, and other countries, indicate that China has completed the process from technology import to technology export, and has caught up with its international competitors.

Both the successful catch-up and the technological innovation of the latecomer industry in emerging markets are worthy of research; however, so far, when summarizing the success of China's high-speed train industry, scholars have proposed different explanations but failed to reach a consensus. For example, Liu et al. [3] argue that basic research has helped the Chinese high-speed train industry acquire the imported technology and fulfill a secondary innovation. They also argue that the government has played a crucial role in coordinating the process of importing and analyzing technology and endogenous innovation. At the same time, the domestic market has also promoted industrial innovation in this sector in China. Sun [4] emphasizes the key role of the government, suggesting that state-led strategic entrepreneurship is the main factor driving technological innovation in the Chinese high-speed train industry. This scholar further argues that the attention to opportunities, deployment, and innovation of resources and strategic learning allows the government to assist the Chinese high-speed train sector's catch-up process. Genin et al. [5] also highlight the government's role in developing China's high-speed train industry and conclude that the government effectively managed Chinese state-owned enterprises in stimulating high-speed train manufacturers.

Existing studies on China's high-speed train industry highlight the efforts of both business firms and the external factors in the catch-up and technological innovation process of this industry in China. The outcome of the joint micro and macro factors is the technological development and understanding gained by domestic firms and the external factors in terms of policy/institution, technology, and demand [6]; however, the previous studies failed to interpret the catch-up and technological innovation process of the Chinese 
high-speed train industry by investigating and understanding its unique nature, namely the complex product and system (CoPS). The Chinese high-speed train industry is widely considered as one typical and common CoPS [7], of which its catch-up and technological innovation processes should be investigated to understand the key mechanisms behind the success.

In studies regarding the high-speed train industry and literature of CoPS, scholars failed to examine the catch-up or innovation processes from the windows of opportunity perspective, which is important for latecomers to gain parity with the leaders and enhance their capabilities [8]. Figure 1 indicates that 2008 and 2013 are two critical times, after which the number of patents shows an accelerated growth pattern in each period. China's high-speed train industry's catch-up process is multifaceted and shaped by joint influence of the government, firms, and windows of opportunities together. We argue that to answer the question of how China's high-speed train industry can successfully catch up, we had to further investigate the role of these windows of opportunity and their impacts on the technological capabilities of domestic firms in this industry.

To answer this question, in this paper, we elaborate on the windows of opportunity of China's high-speed train industry and explore their impacts on the technological capabilities of domestic firms in order to fill the above-mentioned research gaps in the study of CoPS's catch-up research. The rest of this article is as follows: Section 2 reviews the relevant literature from the perspective of CoPS's catch-up and windows of opportunity and presents the conceptual framework of this study; Section 3 describes the research methodology and data of this paper; Section 4 presents the findings of this paper; Section 5 summarizes the empirical findings and connects findings to the theory; and Section 6 concludes the paper and discusses the implications of this study.

\section{Literature Review and Theoretical Development}

\subsection{Catch-Up of CoPS}

A CoPS is a formally hierarchical structure consisting of subsystems or components with complex interactions, which also have their own subsystems or components [9]. CoPS is generally comprised of systems, networks, infrastructure and engineering constructs, and services that are highly costly and technology-intensive $[7,10,11]$. An example of a typical CoPS could be high-speed trains, aircraft, nuclear power plants, and telecommunications switching equipment. CoPS has attracted the attention of both academic researchers and business practitioners due to its importance in technological development and economic influence both for domestic and international contexts [12]; however, due to the complexity and key role of individual countries, the development of CoPS shows a salient divergency and discrepancy between latecomers and developed countries, which has also attracted the attention of many scholars [13], such as researchers investigating the catch-up of latecomers in CoPS.

Current research on the catch-up of CoPS has been conducted in two broad themes. Firstly, some scholars explore the possibility of latecomers successfully engaging in the catch-up process in the CoPS framework-early studies on feasibility were generally negative. Miller et al. [14] and Ren and Yao [10] argue that, in the CoPS sector (sector), advanced economies such as Western countries still maintain leadership comparable to some Asian countries, including Japan. This may be because the CoPS life cycle tends to remain in the fluid phase of product innovation rather than the transition and specific phases of the life cycle model developed by Abernathy and Utterback [15]. Recently, Majidpour's [16] study of Iran's land-based gas turbine industry suggests that CoPS has low variability in technology trajectory, low frequency of technological innovation, and low imitability of system integration capabilities, which often hinders the catch-up process; however, as emerging countries focus more on CoPS-related industries, traditional perceptions regarding the failure of the catch-up process in CoPS started to be questioned. For example, Brazil's aerospace industry [17], Iran's large hydropower system industry [18], and China's telecommunication industry [19] are all considered to be successful cases of 
latecomers' catch-up with the leaders in the CoPS sector. In response to these two conflicting views, Park and Ji [6] argue that latecomers in the CoPS sector have been able to catch up at least in their domestic markets, with a few exceptional ones achieving global leadership.

Another theme of the studies of catch-up in CoPS literature is to explore the key factors that may influence the outcomes of the CoPS catch-up process. Some scholars have highlighted the important role of policy in the CoPS's catch-up process. For example, Binz et al. [20] analyzed the catch-up pattern of China's wind and solar photovoltaics and biomass power industries. These scholars [20] found that top-down industrial policies played an essential role in developing China's wind power industry but a marginal role in the early development of the solar PV industry; therefore, Binz et al. [20] suggest that policymakers in latecomer countries should formulate and design their industrial policies tailored to specific industries. Some other researchers consider innovation as a key factor to the success of the CoPS's catch-up process. Unlike mass production products, a CoPS requires a set of different innovation management techniques [7]. Fan [21] examined the innovation capabilities of four companies in China's telecommunication equipment provider industry and concluded that innovation capabilities and in-house R\&D techniques had become critical in allowing domestic firms to gain parity with multinational incumbents, thus successfully completing the catch-up process. More recently, Park and Ji [6] suggest that the three most important factors affecting the CoPS's catch-up process are government support, building technological capabilities, and domestic industry ecosystems.

In summary, the studies on the catch-up process of CoPS highlight the importance of CoPS to national or industrial developments. The literature also recognizes that the CoPS catch-up process is influenced by multidimensional factors, which requires a holistic view; however, established literature on the CoPS's catch-up process mainly focus on the outcomes (such as the feasibility of the CoPS's catch-up process) or the antecedents (such as the key factors influencing the CoPS's catch-up process), while largely ignoring the catch-up process of CoPS.

\subsection{Windows of Opportunity in the Catch-Up Process}

Technological discontinuity opens a window of opportunity for latecomers to catch up with the leaders [22]. When new technological paradigms emerge, latecomers can quickly shift to new technological trajectories, whereas leaders may be locked into traditional ones (as capability trap or inertia). Consequently, new windows of opportunity emerge due to different statuses and possibilities. In addition to technological windows of opportunity, Mathews [23] examines changes in demand across business cycles and concludes the existence of "demand windows". During a business cycle downturn, the incumbents may fall into a "capability trap", whereas latecomers have lower entry barriers than compared to the standard business cycle and thus have the opportunities to catch up successfully. Studies by Lee and Lim [24] and Guennif and Ramani [8] also suggest that interventions in public policy or dramatic changes in institutional conditions with respect to an industry can also create a policy/institutional window of opportunity for latecomers. Based on these studies, Lee and Malerba [25] further summarize the windows of opportunity into three categories: technology, demand, and policy/institutional windows. Regardless of the category of windows of opportunity, discontinuity is widely considered as its key feature.

Although windows of opportunity can be grouped into three categories from a technology, demand, and policy/institutional perspective, there is still significant uncertainty about the causality and consequences of windows of opportunity. The first is the causal uncertainty of the windows of opportunity. It is often assumed that technological catch-up is directly influenced by policies related to knowledge or technology; however, Guennif and Ramani [8] hold a different opinion and argue that policies related to knowledge or technology may not lead to the emergence of windows of opportunity, while policies not related to knowledge or technology may result in the emergence of a technological window of opportunity, and vice versa. For example, India and Brazil implemented similar policy incentives concerning their respective generic drug industry, but their catch-up 
outcome was different. That is because catch-up is also influenced by the context, timing, and implementation of the policies [24]. The second is the uncertainty of the source of the windows of opportunity. Lee and Malerba [25] point out that windows of opportunity can be exogenous or endogenous, subject to the responses of the various actors in the sectoral system. Even in exogenous technological windows of opportunity, successful latecomers may "endogenize" exogenous innovations.

Some other studies examine the correlations between windows of opportunity and the catch-up process. Guennif and Ramani [8] state that windows of opportunity are a necessary condition for successful catch-up, not a sufficient condition [24]. A recent study by Guo et al. [26] highlights the mutual match between latecomers' capabilities and the windows of opportunity, which may eventually result in synergies for a successful catch-up [25]. Other scholars (such as Ramani and Urias [27]) also admit the importance of a latecomer's capabilities to catch-up outcomes. These researchers believe that latecomers' who lack capabilities in the initial stages should invest in building absorptive capacity and developing reverse engineering skills. In contrast, from the incumbents' perspective, the latecomers' windows of opportunity may lead the incumbents to fall into the capability trap. For example, the incumbent's competitive behaviors are insufficient to maintain a leading position when facing environment changes [27].

Scholars have contributed to the theory of windows of opportunity in recent years, including categories of windows of opportunity and how it affects the catch-up process, but existing studies still lack attention to the following two issues. First, most of the existing studies take it for granted that windows of opportunity work as an exogenous environmental factor, out of the scope of the firm. Thus, the studies of the endogenous windows of opportunity are largely ignored but are still needed. Second, established studies started to explore the features of windows of opportunity and mostly agree that windows of opportunity are interpreted as a one-dimensional concept. Thus, the literature failed to consider the structure of windows of opportunity; either the nested format of windows of opportunity or the multidimensional structure of windows of opportunity are neglected; however, in some contexts such as CoPS, it is necessary to understand and explore windows of opportunity from a multidimensional view.

To fill in the above-mentioned research gaps, we conducted a qualitative inductive analysis on the catch-up process from the perspective of windows of opportunity and technological capabilities in order to understand the innovation process of latecomers in the CoPS industry. We chose the Chinese high-speed train industry as our research context, as it is a typical CoPS industry and a great example. Based on our analysis, we further developed a theoretical framework to illustrate the correlations of windows of opportunities and innovation along with the catch-up process in the CoPS industry of an emerging market. The logic of this theoretical framework lies in the fact that the opening of windows of opportunity is a prerequisite for the occurrence of latecomers' catch-up in the CoPS industry [24,27], and the opening of different windows of opportunity stimulates actors in the CoPS industry to adopt responsive strategies that eventually achieve successful catch-up.

\section{Methodology}

\subsection{Research Context}

We took China's high-speed train industry, a typical CoPS sector, as the research context, to explore its catch-up process through technological innovation. Our aim was to illustrate the relationship between the technological catch-up and innovation in the context of the CoPS industry of latecomer countries. We chose China's High-Speed Train industry due to its importance to the economy and society and its unique role as a CoPS. The lessons and experience of China's High-Speed Rail provide guidelines and insights to other latecomer CoPS industries and countries that are eager to build competence in the context of CoPS. 
The China Railway Rolling Stock Corporation (CRRC) is the largest and only largescale state-owned enterprise engaged in the $R \& D$, manufacturing, and maintenance of highspeed trains in China. It was formed in 2015 by the merger of China South Railway Co., Ltd. (CSR, Beijing, China) and China North Railway Co., Ltd. (CNR, Beijing, China). CRRC's largest and only domestic client is the China State Railway Group Co., Ltd. (formerly known as the Ministry of Railways of China, one of China's government departments), which has the right to purchase and use high-speed train products. In this sense, both the supply and demand sides of China's high-speed trains are managed by state-owned enterprises in China. As a result, the Chinese government can completely control and supervise its high-speed train industry's development process.

\subsection{Research Design}

Considering the complexity of the above-mentioned research question and the specificity of the industrial context, we conducted a longitudinal case study approach. We chose the case study method as our research design for three reasons. First, the case study method can appropriately answer questions related to the process and mechanism; the case study method considers both the holistic view and dynamic nature and can clearly show the conditions, behaviors, and results of technological catch-up dynamics in China's high-speed train industry. Second, the case study method is widely considered an efficient and proper method to examine "how" questions, which fits our research question. Due to China's high-speed train industry's special characteristics, its innovation process has obvious contextualized characteristics and complexity. The longitudinal case study is conducive to understanding the microlevel mechanisms in China's high-speed trains' technological catch-up dynamics. Third, by definition, the longitudinal-case study method is consistent with the multicase study method, which still follows the logic of replication and expansion. By identifying potential causality and improving the case's external validity, we can make the research findings more generalizable, robust, and concise [28,29].

\subsection{Data Source}

The research materials and data were obtained in three ways, including semistructured interviews (details of the interview questions can be found in Appendix A.), detailed secondary data (such as the interior publication of enterprise and published information), and field observation data. Our multisource of data helps our study to ensure credibility through triangulation verification. Doing so allows us to avoid the potential stereotype and retrospective sensemaking problems caused by solely using first-hand data [28]. The first kind of data was first-hand information, which was obtained through in-depth interviews and field observations. In order to improve the reliability and validity of the study, the selected organizations in this study covered different types, as shown in Table 1, including state-owned high-speed train integrators, state-owned key parts suppliers, foreign railway equipment manufacturers, foreign parts suppliers, and a high-speed railway construction firm. Our interviewees were mainly senior managers, technical managers, project managers, and senior engineers who understand the industry and the catch-up process.

From March 2016 to July 2017, we conducted 16 interviews in total. All interviews were tape-recorded with permission. Our interviews were semi-structured to ensure that details could emerge from the interviews. Based on the interview, we also conducted field observations on some integration enterprises and supporting parts enterprises. These field observation experiences helped us to understand the relationship between the whole high-speed train and the core parts, and the key points of technological innovation along with the catch-up process. 
Table 1. Interview breakdown of the Chinese high-speed train industry.

\begin{tabular}{ccccc}
\hline Type of Organization & $\begin{array}{c}\text { \# of } \\
\text { Interviewees }\end{array}$ & $\begin{array}{c}\text { \# of } \\
\text { Interviews }\end{array}$ & Time (min) & $\begin{array}{c}\text { \# of } \\
\text { Visits }\end{array}$ \\
\hline $\begin{array}{c}\text { State-owned high-speed } \\
\text { train integrator }\end{array}$ & 2 & 5 & 241 & 2 \\
$\begin{array}{c}\text { State-owned key parts } \\
\text { suppliers }\end{array}$ & 4 & 4 & 397 & 3 \\
$\begin{array}{c}\text { Foreign railway } \\
\text { equipment }\end{array}$ & 1 & 1 & 64 & $/$ \\
$\begin{array}{c}\text { manufacturers } \\
\text { Foreign parts suppliers } \\
\text { High-speed railway } \\
\text { construction firm }\end{array}$ & 3 & 5 & 506 & 1 \\
Total & 1 & 1 & 120 & $/$ \\
\hline
\end{tabular}

The second kind of data was secondary data, including literature, media reports, government reports, and the internal publications provided by some of the interviewed enterprises. The secondary data were obtained through public channels, including policy documents and plans related to high-speed train issued by government departments, Statistical Bulletins issued by the former Ministry of railways, industry research reports issued by various institutions, and books related to high-speed train development (see Table 2). Our field observation data were mainly sourced via the workplace, working flows, and the factories of railway firms, which helped us to triangulate the other two kinds of data collected.

Table 2. List of secondary information.

\begin{tabular}{ccc}
\hline Secondary Data & \# of Copies & \# of Pages \\
\hline Policy Documents & 72 & 258 \\
Statistical Bulletins & 17 & 167 \\
Research Reports & 7 & 176 \\
Conference Materials & 5 & 364 \\
Total & 101 & 965 \\
\hline
\end{tabular}

Following the requirements and guidelines of the longitudinal case study method, we performed the data analysis using three key steps. First, we divided China's high-speed train industry's development process into different stages and analyzed the windows of opportunity that emerged within each stage, including the key technology innovation of China's high-speed train. Second, we conducted a cross-stage analysis. Following the replication logic and compared with the existing theory, we identified and compared the different stages of the windows of opportunity and technology innovation. Finally, we developed a comprehensive theoretical framework after analyzing and comparing the commonness and difference within and across the catch-up process stages in China's high-speed train industry.

\subsection{Data Analysis}

As Table 3 shows, in order to accurately analyze the data and describe the findings, we clearly defined the three concepts: windows of opportunity, technological capabilities, and catch-up, before we present our core findings.

Windows of opportunity: Drawing on Lee and Malerba's [25] summary of windows of opportunity, we classified the windows of opportunity in the catch-up process of China's high-speed train industry into the technological window, demand window, and policy/institutional window. Regardless of the individual type of window, discontinuity is a core feature. Taking the policy window as an example, a radical policy change can open the window and generate positive externalities in a manner very similar to the radical 
technological discontinuity [24], as the external environment led to the positive possibilities for latecomers.

Table 3. Concept definition.

\begin{tabular}{ccl}
\hline Concepts & Dimensions & \multicolumn{1}{c}{ Definition } \\
\hline $\begin{array}{c}\text { Windows of } \\
\text { opportunity }\end{array}$ & $\begin{array}{c}\text { Technology } \\
\text { Demand } \\
\text { Policy/Institution }\end{array}$ & $\begin{array}{l}\text { The emergence of new technology paradigms or } \\
\text { radical innovations } \\
\text { Significant increase in market demand } \\
\text { Radical policy changes that generate } \\
\text { positive externalities. }\end{array}$ \\
\hline $\begin{array}{c}\text { Technological } \\
\text { capabilities }\end{array}$ & Breadth & $\begin{array}{l}\text { The number of technological fields in which a } \\
\text { firm is active. } \\
(1) \text { The different stages involved in the } \\
\text { technology development process. } \\
\text { (2) Knowledge related to the combination of } \\
\text { key components. }\end{array}$ \\
\hline Catch-up & Catch-up gaps & $\begin{array}{l}\text { Closing the gaps of technology and market } \\
\text { competence with the industry leader. }\end{array}$ \\
\hline
\end{tabular}

Technological capabilities: Our research context of the high-speed trains in China is a typical kind of CoPS. As such, we followed Prencipe's [30] approach to measure the technological capability of the latecomer firm in terms of both breadth and depth. The breadth of technological capability is considered the number of technological fields in which a firm is active, such as control systems or pantograph technology. The measurement of the depth of technological capability includes two dimensions. One is the depth involved in the process of technology development (e.g., conceptual design and detailed design). The other is the knowledge related to the combination of high-speed train components (integration knowledge) or the possible extensions of utilizing the key components.

Please be noted that we take the maximum speed of the Chinese high-speed train as the proxy of technological capability for several reasons. First, the maximum speed of the high-speed train is a widely accepted criterion by both business practitioners in this industry and the public. Second, using the maximum speed of the high-speed train is also reflected by China's government policies as one signal of technological development. Last but not least, the maximum speed of the electrical multiple unit (EMU) will also be influenced by the system of rail, the network of rail, and the technological capabilities of the supporting systems, on top of the technological capability of the high-speed train; however, further analysis of the other influences of the supporting systems was beyond this study's scope; therefore, we took the maximum speed of the train as the proxy of Chinese high-speed train's technological capability.

Catch-up. Some scholars define catch-up from the perspective of capabilities and consider catch-up as the process of accumulation of firms' innovation capabilities [31]. In this manner, the gradual narrowing gaps between latecomers and industry leaders (such as technology competence followed by market competence) is considered a signal that latecomers have succeeded in catch-up [30].

\section{Findings}

\subsection{Background of China's High-Speed Train Industry}

Domestic firms in China started their technological exploration of high-speed trains in 1958, when the project of the Dongfeng diesel multiple unit (DMU) was initiated. Along with developing the speed increase of the major railway, China's independent development of DMUs peaked in the late 20th century. At that time, the maximum designed speed of these products was below $200 \mathrm{~km} / \mathrm{h}$. Those products consist of both centralized and decentralized power products. In the late 1990s, China carried out the development of DMUs, the development of the electrical multiple unit (EMU), and attempts on both centralized 
and decentralized products. Both power-concentrated and power-dispersed products have been tried. EMU is the most successful type of rolling stock in China's independent research and development process during this period, among which the "China Star" mode model reached a maximum speed of $321.5 \mathrm{~km} / \mathrm{h}$ during the test, whereas most of the models of power-dispersed EMUs did not exceed $200 \mathrm{~km} / \mathrm{h}$ in the same period. Meanwhile, China's former Ministry of Railways also tried to explore magnetic levitation trains, but no final products were formally operationalized in the market. During this period, in addition to independent research and development, China also introduced the X2000 pendulum EMU, imported from Sweden, in order to explore the possibility of using the pendulum EMU in China. In general, both power concentration technology and power dispersion technology have been explored, facilitating the technology accumulation for the domestic firms during this period. In terms of technology track selection, domestic rail firms undertook a combination format, which is the development pattern of traditional wheel track technology as the dominant technology and magnetic levitation technology as a complementary one. As for the technology sources, domestic firms mainly adopted the self-development approach to explore different motive train technologies, with selected foreign (imported) products for technology exploration and research; however, the technical capability of domestic firms is still weak, which prevents the domestic firms from mastering the high-speed EMU technology-due especially to the lack of the core components technology. Moreover, the related key materials and knowledge of the production process are also largely behind the international incumbents, requiring further enhancement; however, domestic rail firms accumulated the technology and knowledge at this stage, which led to domestic firms having the capabilities to respond to the windows of opportunity that emerged.

China's high-speed train industry's catch-up process can be roughly divided into three phases: technology imitation, integrated innovation, and original innovation. In what follows, we discuss the windows of opportunity and actor responses in each of the three stages. The windows of opportunity are divided into three categories: technology, demand, and policy; the actors include CRRC companies, relevant government departments, and research institutions.

\subsection{Phase 1: Technology Imitation (2003-2007)}

Due to the urgent needs of China's rapid economic development and the trend of the world's high-speed train technology development, China finally chose to introduce, digest, and absorb foreign advanced technology, rather than independent development, to quickly enhance the technology capability of China's railway industry. In June 2003, the Ministry of Railways highlighted the strategic goal of rapidly expanding transportation capacity and rapidly enhancing technology and equipment. They put forward the idea of developing a railway by designing and implementing the strategy of "leapfrog development", combining original innovation, integrated innovation, and reinnovation by introduction, digestion, and absorption, so as to improve China's high-speed train technology. This policy opened the first window of opportunity for the development of high-speed trains in China. In 2004, the Chinese government formulated the Medium and Long-term Railway Network Plan, proposing a plan to construct $12,000 \mathrm{~km}$ of high-speed railways by 2020 . Such policy discontinuity also opened a policy window-since this policy would also stimulate a significant increase in demand, it also formed a huge demand window.

Under the regulation and supervision of the former Ministry of Railways of China, CRRC introduced four advanced and mature EMU technologies from Alstom (France), Kawasaki Heavy Industries (Japan), Bombardier (Canada), and Siemens (Germany). Unlike the "market-for-technology" model adopted by other Chinese industries (e.g., the automobile industry), the introduction of high-speed trains does not grant market access to foreign enterprises. Instead, the strategy of CRRC is to directly purchase each other's products and technologies from the four leading firms and promote "joint design and production" to domestic firms to master advanced technology. Meanwhile, CRRC imported the advanced technologies from multiple sources and opened a window of technological opportunity for 
domestic firms and expanded the width of their technological capabilities. According to one senior engineer at a state-owned high-speed train integrator:

“...high-speed rail is a national central planning, while automotive is decentralized and managed by individual producers in China. When the Ministry of Railways of China initiated the development of high-speed rail, we have relatively weak technological foundations and less clear scientific vision. What we did is learning by doing with ambition to achieve the final leapfrog development. From the introduction in 2003 to now, we completed the high expectations and requirements of the government over the previous decade, with our energy and efforts, and finally achieved such a remarkably rapid development. We made the history and impressed the world."

At this stage, domestic firms mainly develop adaptive improvements and evolutionary models for the introduced products. Adaptive improvement is mainly used to adapt the introduced models to Chinese routes and operations, including improvements to vehicle bodies, car bodies, service facilities, etc. As a complex product system (CoPS), changes in high-speed trains' local parameters can lead to coupling problems between subsystems. In the process of solving these coupling problems, domestic firms have developed basic integration capabilities and further expanded the depth of their technical capabilities.

\subsection{Phase 2: Integrated Innovation (2008-2012)}

After the digestion and absorption of the imported EMU technology, the independent innovation capability of Chinese domestic firms has improved significantly. As a result, domestic railway companies almost fully realized the independence of the technology source, which further contributes to the integration and innovation based on the imported products. In 2008, the Ministry of Science and Technology and the former Ministry of Railways jointly signed the Joint Action Plan of China High-Speed Railway Independent Innovation Cooperation Agreement. Compared with the former policies, the plan does not show explicit discontinuity and therefore does not constitute a policy window.

Nevertheless, the plan opens a technology window for domestic firms to improve their technological capabilities. The plan proposes developing high-speed trains that meet the operational needs of the Beijing-Shanghai high-speed railway system and increase the EMU's speed from 250-300 to $350 \mathrm{~km} / \mathrm{h}$ and/or even above the limit of $350 \mathrm{~km} / \mathrm{h}-$ at that time, the China South Railway Group and the North Railway Group finished their process of digesting and absorbing relevant foreign technologies and built their knowledge base. To realize the strategic plan, the former Ministry of Railways of China coordinated a cross-organizational project, which consisted of a science and technology team including 6 large national mega state-owned enterprises, 25 key universities, 11 firstclass research institutions, 51 national laboratories and engineering centers, and a team of 68 academicians, 500 professors, and more than 10,000 engineers and technicians [2]. Consequently, CRRC realized the remarkable product of integrated innovation, CRH380 series EMUs, based on the imported technology platform. Meanwhile, the depth of technological capability of domestic firms improved significantly during the process; however, some core components of the CRH380 series EMU are still provided by Siemens and other international railway companies. In this period, domestic firms were able to integrate core components from different sources (most imported from leading international leaders) dedicated to market demand and the manufacture of the high-speed EMU, which is capable of reaching $380 \mathrm{~km} / \mathrm{h}$. According to one manager of strategic planning at a state-owned key parts supplier:"In 2010, we fully achieved in-house manufacturing of core components for the CRH380A high-speed locomotive".

More importantly, domestic railway firms achieved some breakthroughs in key technologies such as train bodies and traction systems. The more typical ones are the cold and sand resistant EMU developed to adapt to the harsh environmental factors like high altitude, sand, and high cold. For example, Qingdao Sifang (CRRC Subsidiary) developed the CRH2G EMU in 2014, whereas Changchun Railway Vehicles (CRRC Subsidiary) devel- 
oped the CRH380BG and CRH5G in 2012 and 2014, respectively. According to one senior engineer at one state-owned high-speed train integrator:

"For example, from Wuhan to Harbin by train, you just think about how many places you have experienced. In winter, the temperature in Harbin can be minus 20 to 30 degrees, while in Wuhan it can be more than 10 degrees above zero. European countries will not experience such a big divergence of temperature from one place to the other. Therefore, such kind of cold-resistant train is not available abroad. But our products can afford the scenarios of minus 40 degrees, which can only be produced by our company. Under the help of big data accumulated in our operations, our products are able to adapt to any climatic conditions".

Those star products are considered durable to operate in extreme hot and cold environments to access the divergent geographic regions of China. These independently developed EMU products indicate that the railway firms in China have mastered the design and manufacturing capability of multispectrum EMU.

In addition, the Chinese government also amended the Medium and Long-Term Railway Network Plan in 2008, which planned to revise the target of 12,000 km of highspeed railways to $16,000 \mathrm{~km}$ by 2020 . The significant increase in railway line mileage aims to drive the demand for high-speed trains from major railway authorities; thus, it continues and extends the previous window of opportunity for demand.

\subsection{Phase 3: Original Innovation (2013-2019)}

Multiple different technology sources from different international leading firms provided a good opportunity for the rapid development of China's high-speed train industry; however, it also led to the coexistence of multiple technology platforms and multiple products. There were 17 types of EMUs from 4 technology platforms in China, with many different models and divergent technical standards, and differences in passenger interface, operation interface, control mode, and maintenance interface.

To solve this problem of fragmentation, since 2012, the former Ministry of Railways of China united domestic firms, universities, scientific research units, and other advantageous forces to develop the $350 \mathrm{~km} / \mathrm{h}$ Chinese standard EMU. In June 2013, the "China Standard" EMU project was officially launched, aiming at in-house technology development. The technical conditions of key components such as the braking system and electrical system are regulated accordingly to prepare for the unified certification of EMU parts. According to one senior engineer at the manufacturing department of a state-owned key parts supplier:

"At that time, the standards of domestic rolling stock are divergent in China. For instance, some of the rolling stock is adapted to the Japanese environment, and then it is the Japanese standard. Some others were imported from Europe, and then it may be some of the European standards. And some rolling stocks are imported from France, and then its standard is the French standard. The CRC has proposed a lot of standards to meet the domestic needs, in order to create a new kind of rolling stock based on Chinese standards. That is, the Fuxing. In 2015, we completed the rolling stock for Fuxing, which is called the Chinese standard rolling stock".

In 2017, the Chinese standard EMU was officially named the Fuxing CR400 series and was put into commercial operation at $350 \mathrm{~km} / \mathrm{h}$ on the Beijing-Shanghai high-speed railway in the same year. Although the introduction of the Chinese standard implies a further increase in the breadth of domestic firms' technical capability, the introduction of the technical standard did not create a window of opportunity. The main reason is that the standard's main purpose is to establish a technology platform for endogenous innovation, unify the technology standards, and produce the EMU products based on the standard; however, in reality, a product such as the CR400AF still has a speed of $350 \mathrm{~km} / \mathrm{h}$.

In addition, in 2016, the Chinese government revised the Medium and Long-Term Railway Network Plan again. The government increased the target of building high-speed railways to $30,000 \mathrm{~km}$ by 2020 and proposed roughly $38,000 \mathrm{~km}$ of high-speed railways by 2025. Despite the change in the planned rail mileage, this is not a policy window but a 
huge demand window. There has been no radical shift in the policy objective compared to that of 2004 when the plan was proposed.

Through the analysis mentioned above, we found that the windows of opportunity in China's high-speed train industry show a changing trend, as shown in Table 4. In terms of the industrial development process, the number of windows of opportunity in the technology imitation phase is the largest, and then decreases gradually. From the classification of windows of opportunity, the number of demand windows is the largest, whereas the number of policy windows is the least. All demand windows are stimulated by government policies or government policies "endogenized" demand windows. From the perspective of CoPS, there are also some differences between the two technology windows. The technology opportunity in the technology imitation phase focuses on expanding the breadth of the technological capability of domestic firms. In contrast, the technology opportunity in the integrated innovation phase focuses on deepening the depth of the technological capability of domestic firms.

Table 4. Windows of opportunity in China's high-speed train industry.

\begin{tabular}{|c|c|c|c|}
\hline & $\begin{array}{c}\text { Phase } 1 \\
\text { Technology Imitation }\end{array}$ & $\begin{array}{c}\text { Phase } 2 \\
\text { Integrated Innovation }\end{array}$ & $\begin{array}{c}\text { Phase } 3 \\
\text { Original Innovation }\end{array}$ \\
\hline Institutional/policy window & $\begin{array}{l}\text { The Chinese government } \\
\text { proposed "leapfrog } \\
\text { development" in } 2003 . \\
\text { In 2004, the Chinese } \\
\text { government proposed the } \\
\text { Medium and Long-term } \\
\text { Railway Network Plan. }\end{array}$ & N.A. & N.A. \\
\hline Technological window & $\begin{array}{l}\text { Domestic firms have } \\
\text { introduced technologies from } \\
\text { four countries. } \\
\text { Domestic firms produce EMU } \\
\text { with a speed of } 250 \mathrm{~km} / \mathrm{h} \text {. }\end{array}$ & $\begin{array}{l}\text { Domestic firms produce EMU } \\
\text { with a speed of } 350 \mathrm{~km} / \mathrm{h} .\end{array}$ & N.A. \\
\hline Demand window & $\begin{array}{l}\text { Chinese government } \\
\text { proposed to build } 12,000 \mathrm{~km} \\
\text { of high-speed railways by the } \\
\text { end of } 2020 .\end{array}$ & $\begin{array}{l}\text { Chinese government revised } \\
\text { the plan to build } 16,000 \mathrm{~km} \\
\text { railways by the end of } 2020 \text {. }\end{array}$ & $\begin{array}{l}\text { Chinese government again } \\
\text { revised the plan to build } \\
30,000 \mathrm{~km} \text { railways by the end } \\
\text { of } 2025 \text {. }\end{array}$ \\
\hline
\end{tabular}

Notes: N.A. means there is not a window of opportunity.

\section{Discussions}

Previous studies have classified the types of windows of opportunity, which can be divided into three categories based on their respective causes: technology, demand, and policy/institutional; and from sources: endogenous and exogenous [8]. These taxonomies provide a deeper understanding of windows of opportunity but still do not fully elucidate the variations of windows of opportunity. Based on the experience of China's high-speed train industry development, we summarize three possible characteristics of the windows of opportunity for CoPS's catch-up: endogeneity, asymmetry, and relevance.

Endogeneity: Indeed, many windows of opportunity have emerged in the catch-up process of China's high-speed train industry; however, we found that the government has formed these windows of opportunity through the formulation of industrial policies with specific objectives. Since CRRC is the only supplier of Chinese high-speed trains, these industrial policies can be well implemented from macro to micro levels. A review study of CoPS's catch-up by Park and Ji [6] also emphasizes the important role of government support.

Asymmetry: In the early stages of CoPS's catch-up, because of the large gap between latecomers and leaders in terms of technological capabilities and market shares, the government can benchmark this gap to formulate industrial policies, facilitating the creation of endogenous policy windows of opportunity. Meanwhile, the contents of policy can determine whether the technological and demand windows open. When entering the 
late stage of catch-up, the gap between the latecomers and the leaders gradually narrows, leading to a diminishing window of opportunity. In other words, there is an asymmetry of the windows of opportunity between the early and late stages of CoPS's catch-up.

Relevance: We also identified the relevance of windows of opportunity along with the development of the Chinese high-speed train industry. For example, in 2004, the Chinese government proposed the Medium and Long-Term Railway Network Plan, which proposed to build $12,000 \mathrm{~km}$ of high-speed railways by 2020 . This policy plan is not a continuation of previous policies and creates a huge discontinuity with previous industrial policies, thus creating a policy window; however, the plan proposes the construction of high-speed rail targets, which also formed a demand window at the same time. In this sense, the policy discontinuity may also form a demand and technology window, which further extends the view by Guennif and Ramani [8].

In addition, based on the classification of CoPS technological capabilities [29], we believe that technological windows can be more carefully classified into windows of opportunity for expanding technological breadth and windows of opportunity for deepening technological depth. This classification can help us understand the relationship between CoPS's catch-up and technology opportunities more clearly. From the case of China's high-speed train catch-up, the early stage of CoPS's catch-up should focus more on expanding the width of technological opportunities and then gradually deepening the depth of technological opportunities.

At present, the COVID-19 pandemic still impacts most of the countries in the world. To control the spread of the pandemic, many governments have initiated various restrictive policies of travel, resulting in a continued downturn in the rail transportation market; however, the downturn in the transportation market is accompanied by the growth of the cargo market. In China, for example, in 2020, the railroad cargo delivery volume reached 3.58 billion tons, with an increase of $4.1 \%$ year-on-year [32]; therefore, building a sustainable railroad transportation market requires governments and business firms to explore how to convert idle passenger capacity into freight capacity to meet the needs of the current situation. We believe that the ongoing pandemic may form a new window of opportunity for those firms that are adaptive and innovative, which may also benefit the long-term sustainable development.

\section{Conclusions}

\subsection{Contributions}

Based on the CoPS's catch-up literature and windows of opportunity theory, in this study, we adopted a longitudinal case study approach to illustrate the impact of the windows of opportunity in the catch-up process of China's high-speed train industry. Our theoretical contribution of this paper lies in three main points.

First, we summarized the characteristics of the windows of opportunity in the CoPS's catch-up process, including endogeneity, asymmetry, and relevance. In contrast, the previous studies in the catch-up field have not explored the process for CoPS. Our study fills this gap and refines their characteristics.

Second, our study provides new insights to understand the concept of windows of opportunity. Lee and Malerba [8] pointed out that the windows of opportunity can be endogenous or exogenous but largely neglected the correlation between endogenous windows of opportunity. In the CoPS industry, endogenous policy windows may lead to demand windows and technology windows.

Third, our findings show that technology opportunities in the CoPS industry are not always homogeneous. There are often significant differences in technology windows at different phases of CoPS's catch-up. Some technology windows open more favorably for firms to develop the breadth of technological capabilities, whereas others are more favorable for developing the depth of technological capabilities. 


\subsection{Implications}

This study's findings can help governments of latecomer countries better formulate CoPS industrial policies, followed by a gradual progress in achieving catch-up with leading countries. First, the governments of latecomer countries should formulate industrial policies with clear objectives to open the windows of opportunity. Especially at the early stage of catch-up, the government can introduce policies with different objectives, thus forming an endogenous window of technology and demand. Second, policymakers and business executives should focus on developing the technological capabilities of domestic firms. Usually, CoPS may involve very complex technologies. The technical boundaries of CoPS are wider and deeper compared with the mass-produced products, thus requiring higher technical capabilities of domestic firms. When building technical capabilities, domestic firms need to choose between technical breadth and depth due to the limitations of their initial capabilities and resources.

Despite China's high-speed train industry's success over the past decade, the model of industrial development driven by an endogenous window of opportunity is not perfect. First, this model may have limitations across industry applications. As Guennif and Ramani [8] argue, there are always unpredictable reactions to the government's approach of facilitating industrial developments through an endogenous window of opportunity. For example, in China's auto industry, the Chinese government proposed a "market-fortechnology" policy to create a window of opportunity in the 1980s to develop the auto industry; however, by the end of the policy implementation, local Chinese firms were still lagging behind in key technologies. Second, this model may also have regional limitations. The success of the Chinese model is based on the large market size of railroad transportation, which reached 3.66 billion passenger trips in 2019, including 2.29 billion on high-speed railroads. The size of China's rail passenger traffic is four times more than that of Europe's or Japan's high-speed rail networks [2]. The huge market capacity also creates room for the growth of the technological capabilities of domestic firms. Further, China's high-speed train market is an institutionally driven market [33], where the government can strategically intervene in the development plans and endorse them with institutional policies and resources. Unlike China, most other countries are unlikely to have both conditions available; therefore, for countries that are eager to learn from the successful experience of China's high-speed train industry, policymakers need to consider the potential joint influences of the characteristics of the domestic market and the windows of opportunity resulted from government's policies.

At present, the COVID-19 (Coronavirus Disease 2019) pandemic still impacts most of the countries in the world. To control the spread of the pandemic, many governments have initiated various restrictive policies of travel, resulting in a continued downturn in the rail transportation market; however, the downturn in the transportation market is accompanied by the growth of the cargo market. In China, for example, in 2020, the railroad cargo delivery volume reached 3.58 billion tons, with an increase of $4.1 \%$ year-on-year [32]; therefore, building a sustainable railroad transportation market requires governments and business firms to explore ways to convert idle passenger capacity into freight capacity to meet the needs of the current situation. We believe that the ongoing pandemic may form a new window of opportunity for those firms that are adaptive and innovative, which may also benefit the long-term sustainable development.

\subsection{Limitations and Future Research}

This study's limitation is that we only examined the high-speed rail industry and lacks comparisons with other CoPS industries. Consequently, we still do not know whether exogenous windows of opportunity in the CoPS industry can lead to catch-up and know little about whether endogenous and exogenous windows of opportunity can lead to different outcomes. Moreover, this study does not include the firm capability building process. We only considered the technological capabilities of latecomer firms due to the firms' response to the windows of opportunity. 
Future research can consider a multicase comparative study of CoPS industries to further explore the impacts of opening the windows of opportunity on the catch-up process of a CoPS via a case comparison approach. It is also recommended to consider the process of enterprise capability building incorporated into the research framework to explore the interactions between the windows of opportunity and capability building of latecomers.

Author Contributions: H.H. contributed to the research problem, co-collected data, and wrote the manuscript for initial submission and manuscript revision for resubmission. J.X. designed the research framework, cocollected data, and revised the manuscript for initial submission, and manuscript revision for resubmission. J.Z. helped with the framing of research and contributed to manuscript revision for initial submission and manuscript proofreading for resubmission. All authors have read and agreed to the published version of the manuscript.

Funding: This research received no external funding.

Institutional Review Board Statement: Not applicable.

Informed Consent Statement: Not applicable.

Data Availability Statement: Not applicable.

Conflicts of Interest: This study has no conflict of interest.

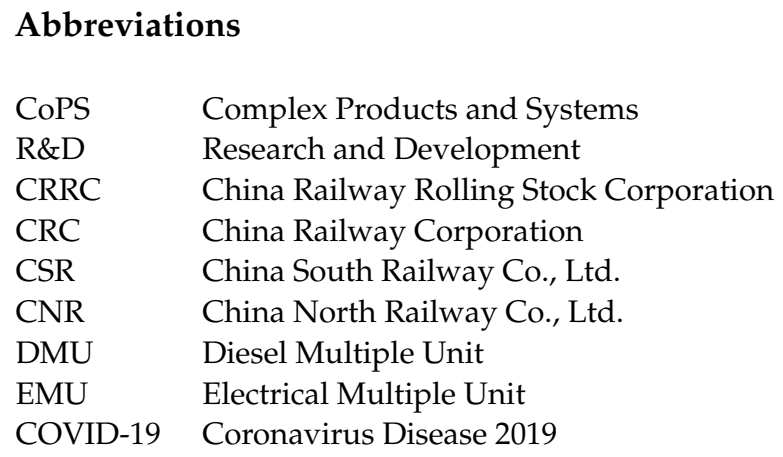

\section{Appendix A}

In this study, interviews were conducted using semi-structured interviews based on the following themes. During the interviews, we allowed the interviewees to improvise their answers within the scope of the themes. Meanwhile, after each interview we compared the results with the theoretical framework before deciding who and what to focus on for the next interview.

1. We first asked the interviewees about their work experience in the railway equipment industry.

2. Can you talk about the process of technology introduction, absorption and innovation in China's high-speed train industry?

3. At the macro level, what are the influencing factors for the rapid development of China's high-speed train industry?

4. What are the key events in the development of China's high-speed train industry? How did they influence the industrial development?

5. How has your company's technological capability grown since the introduction of foreign high-speed train technology in China since 2003? What were the key events?

\section{References}

1. People's Daily. High-speed Rail Mileage Doubled in Five Years. (In Chinese). Available online: http://cpc.people.com.cn/n1/2 021/0131/c64387-32017825.html (accessed on 6 February 2021).

2. Lawrence, M.; Bullock, R.; Liu, Z.M. China's High-Speed Railroad Development (in Chinese); World Bank: Washington, DC, USA, 2019.

3. Liu, X.; Cheng, P.; Chen, A. Basic Research and Catch-up in China's High-Speed Rail Industry. J. Chin. Econ. Bus. Stud. 2011, 9 , 349-367. [CrossRef] 
4. Sun, Z. Technology Innovation and Entrepreneurial State: The Development of China's High-Speed Rail Industry. Technol. Anal. Strateg. Manag. 2015, 27, 646-659. [CrossRef]

5. Genin, A.L.; Tan, J.; Song, J. State Governance and Technological Innovation in Emerging Economies: State-Owned Enterprise Restructuration and Institutional Logic Dissonance in China's High-Speed Train Sector. J. Int. Bus. Stud. 2020. [CrossRef]

6. Park, T.; Ji, I. Evidence of Latecomers' Catch-up in CoPS Industries: A Systematic Review. Technol. Anal. Strateg. Manag. 2020, 32, 968-983. [CrossRef]

7. Hobday, M. Product Complexity, Innovation and Industrial Organisation. Res. Policy 1998, 26, 689-710. [CrossRef]

8. Guennif, S.; Ramani, S.V. Explaining Divergence in Catching-Up in Pharma Between India and Brazil Using the NSI Framework. Res. Policy 2012, 41, 430-441. [CrossRef]

9. Davies, A. The Life Cycle of a Complex Product System. Int. J. Innov. Manag. 1997, 01, 229-256. [CrossRef]

10. Ren, Y.-T.; Yeo, K.-T. Research Challenges on Complex Product Systems (CoPS) Innovation. J. Chin. Inst. Ind. Eng. 2006, 23, 519-529. [CrossRef]

11. Lee, J.J.; Yoon, H. A Comparative Study of Technological Learning and Organizational Capability Development in Complex Products Systems: Distinctive Paths of Three Latecomers in Military Aircraft Industry. Res. Policy 2015, 44, 1296-1313. [CrossRef]

12. Hansen, K.L.; Rush, H. Hotspots in Complex Product Systems: Emerging Issues in Innovation Management. Technovation 1998, 18, 555-590. [CrossRef]

13. Hidalgo, C.A.; Klinger, B.; Barabási, A.L.; Hausmann, R. The Product Space Conditions the Development of Nations. Science 2007, 317, 482-487. [CrossRef] [PubMed]

14. Miller, R.; Hobday, M.; Leroux-Demers, T.; Olleros, X. Innovation in Complex Systems Industries: The Case of Flight Simulation. Ind. Corp. Chang. 1995, 4, 363-400. [CrossRef]

15. Abernathy, W.J.; Utterback, J.M. Patterns of Industrial Innovation. Technol. Rev. 1978, 80, 40-47.

16. Majidpour, M. Technological Catch-Up in Complex Product Systems. J. Eng. Technol. Manag. 2016, 41, 92-105. [CrossRef]

17. Maculan, A.M. Embraer and the Growth of the Brazilian Aircraft Industry. Int. J. Technol. Glob. 2013, 7, 41. [CrossRef]

18. Kiamehr, M. Paths of Technological Capability Building in Complex Capital Goods: The Case of Hydro Electricity Generation Systems in Iran. Technol. Forecast. Soc. Chang. 2017, 122, 215-230. [CrossRef]

19. Mu, Q.; Lee, K. Knowledge Diffusion, Market Segmentation and Technological Catch-Up: The Case of the Telecommunication Industry in China. Res. Policy 2005, 34, 759-783. [CrossRef]

20. Binz, C.; Gosens, J.; Hansen, T.; Hansen, U.E. Toward Technology-Sensitive Catching-Up Policies: Insights from Renewable Energy in China. World Dev. 2017, 96, 418-437. [CrossRef]

21. Fan, P. Catching Up Through Developing Innovation Capability: Evidence From China's Telecom-Equipment Industry. Technovation 2006, 26, 359-368. [CrossRef]

22. Perez, C.; Soete, L. Catching Up in Technology: Entry Barriers and Windows. In Technical Change and Economic Theory Technical Change and Economic Theory; Giovanni, D., Richard, N., Gerald, S., Luc, S., Eds.; Pinter: London, UK, 1988; pp. $458-479$.

23. Mathews, J.A. Strategy and the Crystal Cycle. Calif. Manag. Rev. 2005, 47, 6-32. [CrossRef]

24. Lee, K.; Lim, C. Technological Regimes, Catching-Up and Leapfrogging: Findings From the Korean Industries. Res. Policy 2001, 30, 459-483. [CrossRef]

25. Lee, K.; Malerba, F. Catch-Up Cycles and Changes in Industrial Leadership: Windows of Opportunity and Responses of Firms and Countries in the Evolution of Sectoral Systems. Res. Policy 2017, 46, 338-351. [CrossRef]

26. Guo, L.; Zhang, M.Y.; Dodgson, M.; Gann, D.; Cai, H. Seizing Windows of Opportunity by Using Technology-Building and Market-Seeking Strategies in Tandem: Huawei's Sustained Catch-up in the Global Market. Asia Pac. J. Manag. 2019, 36, 849-879. [CrossRef]

27. Ramani, S.V.; Urias, E. When Access to Drugs Meets Catch-Up: Insights From the Use of Cl Threats to Improve Access to Arv Drugs in Brazil. Res. Policy 2018, 47, 1538-1552. [CrossRef]

28. Eisenhardt, K.M. Better Stories and Better Constructs: The Case for Rigor and Comparative Logic. Acad. Manag. Rev. 1991, 16, 620-627. [CrossRef]

29. Eisenhardt, K.M.; Graebner, M.E. Theory Building From Cases: Opportunities and Challenges. Acad. Manag. J. 2007, 50, 25-32. [CrossRef]

30. Prencipe, A. Breadth and Depth of Technological Capabilities in CoPS: The Case of the Aircraft Engine Control System. Res. Policy 2000, 29, 895-911. [CrossRef]

31. He, X.; Mu, Q. How Chinese Firms Learn Technology from Transnational Corporations: A Comparison of the Telecommunication and Automobile Industries. J. Asian Econ. 2012, 23, 270-287. [CrossRef]

32. CCTV. Steady Growth in National Rail Freight Volume in 2020. (In Chinese). Available online: http://m.news.cctv.com/2021/01/ 05/ARTIGgtSKny5wFpqgubQGWhB210105.shtml (accessed on 6 February 2021).

33. Wei, J.; Sun, C.; Wang, Q.; Pan, Q. The Critical Role of the Institution-led Market in the Technological Catch-up of Emerging Market Enterprises: Evidence from Chinese Enterprises. $R \mathcal{E} D$ Manag. 2020. [CrossRef] 